\title{
CoCrMo-base Alloys for Dental Applications Obtained by Selective laser melting (SLM) and CAD/CAM Milling
}

\author{
Claudinei dos Santos ${ }^{a, b, *}$ (D), Alexandre Fernandes Habibe ${ }^{b, c}$, Bruno Galvão Simba ${ }^{d}$, \\ Jefferson Fabrício Cardoso Lins ${ }^{b}$, Bruno Xavier de Freitas ${ }^{e}$, Carlos Angelo Nunes ${ }^{e}$ (D) \\ ${ }^{a}$ Universidade do Estado do Rio de Janeiro - UERJ, Faculdade de Tecnologia - FAT, Rod. Presidente \\ Dutra, km 298, CEP 27537-000, Polo Industrial, Resende, RJ, Brasil \\ ${ }^{\mathrm{b}}$ Universidade Federal Fluminense - UFF, Escola de Engenharia Industrial Metalúrgica de Volta Redonda \\ - EEIMVR, Av. Trabalhadores, 420, CEP 27255-125, Vila Santa Cecília, Volta Redonda, RJ, Brasil \\ 'Centro Universitário de Volta Redonda- UNIFOA, Av. Paulo Erlei Alves Abrantes, 1325, \\ CEP 27240-560, Três Poços, Volta Redonda, RJ, Brasil \\ 'Universidade Estadual Paulista - UNESP, Faculdade de Engenharia de Guaratinguetá -FEG, \\ Av. Ariberto Pereira da Cunha, 333, CEP 12516-410, Portal das Colinas, Guaratinguetá, SP, Brazil \\ ${ }^{\mathrm{e}}$ Universidade de São Paulo - USP, Escola de Engenharia de Lorena - EEL, área II, \\ Polo Urbo Industrial Gleba AI6, s/n, CEP 12600-000, Lorena, SP, Brasil
}

Received: October 29, 2019; Revised: April 12, 2020; Accepted: April 14, 2020

\begin{abstract}
In this work, CoCrMo-base alloys specimens were produced by additive manufacturing using selective laser melting (SLM) as well as CAD/CAM milling. For SLM specimens, spherical particles were laser processed at $1320^{\circ} \mathrm{C}$ under argon atmosphere and submitted to thermal stress relieving at $750^{\circ} \mathrm{C}-45 \mathrm{~min}$. Specimens from CoCrMo blocks were milled by $\mathrm{CAD} / \mathrm{CAM}$ machining and sintered at $1300^{\circ} \mathrm{C}-60 \mathrm{~min}$. The materials from both techniques were characterized by relative density, dilatometry, $\mathrm{SEM}$ /BSE, OM and XRD analysis. The mechanical properties were determined by Vickers hardness and tensile tests. The specimens from both techniques exhibited single phase $\gamma$ Co (FCC) and CTE of $14 \times 10^{-6}{ }^{\circ} \mathrm{C}^{-1}$. Relative density of $95.4 \% / 85.6 \%$, hardness values near $400 \mathrm{HV} / 350 \mathrm{HV}$ and UTS of $905 \mathrm{MPa} / 780 \mathrm{MPa}$ were measured for SLM and CAD/CAM specimens, respectively. Higher relative density is the main factor for increased mechanical properties of SLM specimens. On the other hand, both SLM and CAD/CAM specimens present properties in accordance with ISO-22674 recommendations, compatible with dental applications such as bridges containing four or more elements as well as fully dense pontics.
\end{abstract}

Keywords: Dental alloys, CoCrMo metal system, additive manufacturing, selective laser melting, CAD/CAM milling, microstructural characterization, mechanical properties.

\section{Introduction}

CoCrMo alloys are commonly used for dental restorations due to their high corrosion resistance, good mechanical properties and biocompatibility ${ }^{1-3}$. Dental components have been produced from these alloys by prototyping techniques, classified in two groups: additive manufacturing, such as Selective Laser Melting (SLM) technique and subtractive manufacturing, such as the milling of pre-manufactured materials assisted by CAD/CAM (Computer Aided Design/Computer-Aided Manufacturing $)^{4-7}$.

Selective laser melting (SLM) or Selective laser sintering (SLS) are prototyping techniques where the components designed in a 3D software are manufactured by depositing thin layers of powders with simultaneous in situ melting/sintering of the material. The heat source is usually a laser beam which heat up the material to a suitable temperature, allowing either diffusion in solid state or melting,

\footnotetext{
*e-mail: claudineisvr@gmail.com
}

producing components of any format with accuracy in the micrometer-scale ${ }^{8-11}$. The manufacture speed is similar to that via $\mathrm{CAD} / \mathrm{CAM}$ and the main advantages are: dimensional accuracy; the possibility to form complex geometries; no use of machining tools and better metallic yield, as the raw material is fully converted to the final product. One of the main disadvantages of this technique is the development of temperature gradients during fabrication of the component, leading to residual thermal stresses which may reduce its mechanical properties ${ }^{9,11-13}$.

Previous investigations using SLM prototyping technique have been published targeting to understand the microstructural features of the CoCrMo alloys aiming to produce biomedical devices ${ }^{14,15}$. Barucca et al. ${ }^{16}$ evaluated the microstructural evolution of $\mathrm{CrCoMo}$ dental restorations made by direct metal laser sintering and confirmed the phase transformation from $\gamma \mathrm{Co}$ (FCC) to $\varepsilon \gamma \mathrm{Co}$ (HCP). Zhou et al. ${ }^{17}$ found $72 \mathrm{vol} \%$ of structured $\gamma \mathrm{Co}$ (FCC) phase after SLM process and subsequent heat treatments at $1150{ }^{\circ} \mathrm{C}$ for $1 \mathrm{~h}$. Furthermore, 
Qian et al. ${ }^{18}$ detailed microstructure changes, particular those related to the welding pool boundaries, grain and sub-grain boundaries, their results showing that rapid cooling keeps the high-temperature $\gamma \mathrm{Co}$ (FCC) phase and promotes a cellular sub-grain structure characterized by Mo fluctuation and inhibits carbide formation.

In this work, CoCrMo-base specimens were manufactured by SLM and evaluated in terms of their microstructures and mechanical properties (hardness and tensile tests). A commercial CoCrMo block used to produce dental metallic restorations by $\mathrm{CAD} / \mathrm{CAM}$ was conventionally sintered to obtain data for comparison with the SLM produced specimens.

\section{Experimental Procedure}

\subsection{Materials}

Table 1 shows the chemical composition determined by X-ray fluorescence spectroscopy (XRF) (PANalytical Axios advanced) of the CoCrMoW powder used for SLM experiments in this work as well as that of the Ceramill Sintron ${ }^{\circledR}$ block (Amman Girrbach AG - Austria) which was machined and conventionally sintered to be compared with the SLM product.

\subsection{Processing}

The CoCrMoW powder was laser processed at $1320^{\circ} \mathrm{C}$ to initially manufacture cylindrical specimens of $\varnothing 3 \mathrm{~mm} \times 6 \mathrm{~mm}$ under argon atmosphere, using an EOSINT M280-EOS equipment with a Yb-fiber laser of $200 \mathrm{~W}$, STL CAD interface, scan speed of $700 \mathrm{~mm} / \mathrm{s}$ and layer thickness of $20 \mu \mathrm{m}$. The specimens were then heat treated at $750^{\circ} \mathrm{C}-45 \mathrm{~min}$. under argon atmosphere for stress relieve, using a Maitec F1150 Furnace. These cylindrical specimens were used for microstructural characterization as well as for hardness measurements. Following the same procedure above, tensile specimens were manufactured by SLM with dimensions shown in Figure 1a. Figure 1b illustrates the relative orientation of the tensile specimens with respect to the powder deposition direction.

Specimens of $5 \times 5 \times 10 \mathrm{~mm}$ dimensions were removed from CoCrMo Ceramill Sintron block (AmannGirrbach; Austria) and sintered at $1300^{\circ} \mathrm{C}-60$ min under argon atmosphere. These specimens were used for microstructural characterization as well as for hardness measurements. In addition, tensile specimens with the same dimensions of the SLM tensile specimens were removed by CAD/CAM from the Ceramill Sintron block, as indicated in Figure 1c, and also sintered at $1300^{\circ} \mathrm{C}-60 \mathrm{~min}$.

All the tensile specimens were grounded with $\mathrm{SiC}$ paper (\#1200) before tests to minimize surface effects on the tensile tests data.

\subsection{Microstructural and mechanical characterization of raw materials and sintered specimens}

The raw materials (CoCrMoW powder and CoCrMo Ceramill Sintron block) and the processed materials were characterized via X-ray diffraction (XRD) and scanning electron microscopy (SEM) in the back-scattered electrons image mode (BSE).

The XRD experiments were carried out in a Shimadzu XRD6100 equipment using $\mathrm{Cu}-\mathrm{K} \alpha$ radiation; scanning between $20^{\circ}$ and $80^{\circ}$, step size of $0.05^{\circ}$ and counting time of $3 \mathrm{~s} /$ point. The phases present in the specimens were identified from Crystalographica Search-Match software (Oxford Cryosystems) ${ }^{19}$.

SEM/BSE images from the raw-materials were obtained from a Hitachi TM 3000 SEM at $15 \mathrm{kV}$ and $8.5 \mathrm{~mm}$ working distance. The processed materials were characterized by optical microscopy (Leica DM IRM) from flat and polished samples,

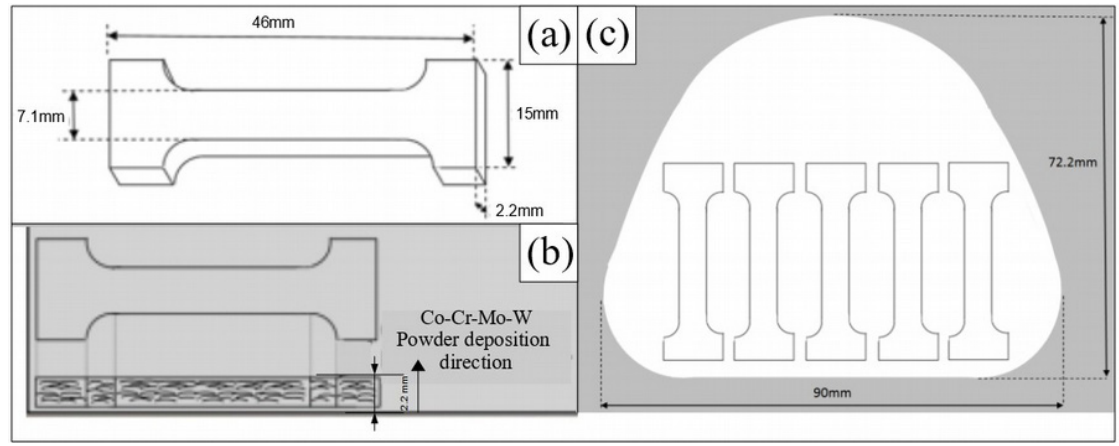

Figure 1. (a) Dimensions of the tensile tests specimens (b) Relative orientation of the SLM tensile specimens with respect to the powder deposition direction (c) Schematic top view of the CoCrMo block with indication of the tensile specimens removed by CAD/CAM.

Table 1. Chemical composition of the alloys used in the present study (wt.\%)

\begin{tabular}{|c|c|c|c|c|c|c|c|c|c|}
\hline Material & Processing & Co & $\mathrm{Cr}$ & Mo & W & $\mathbf{S i}$ & Mn & $\mathbf{F e}$ & Others \\
\hline $\begin{array}{l}\text { CoCrMoW } \\
\text { EOS SP2 } \\
\text { (Atomized - Germany } \\
\text { (Ater) }\end{array}$ & $\begin{array}{l}\text { Selective laser melting } \\
\text { (SLM) }\end{array}$ & 61.6 & 25.6 & 6.2 & 5.5 & 0.5 & 0.1 & 0.2 & 0.3 \\
\hline $\begin{array}{l}\text { CoCrMo } \\
\text { Ceramill Sintron block, } \\
\text { AmmanGirrbach - Austria }\end{array}$ & Solid state sintering & 64.4 & 28.4 & 5.6 & - & 0.2 & 0.9 & 0.2 & 0.3 \\
\hline
\end{tabular}



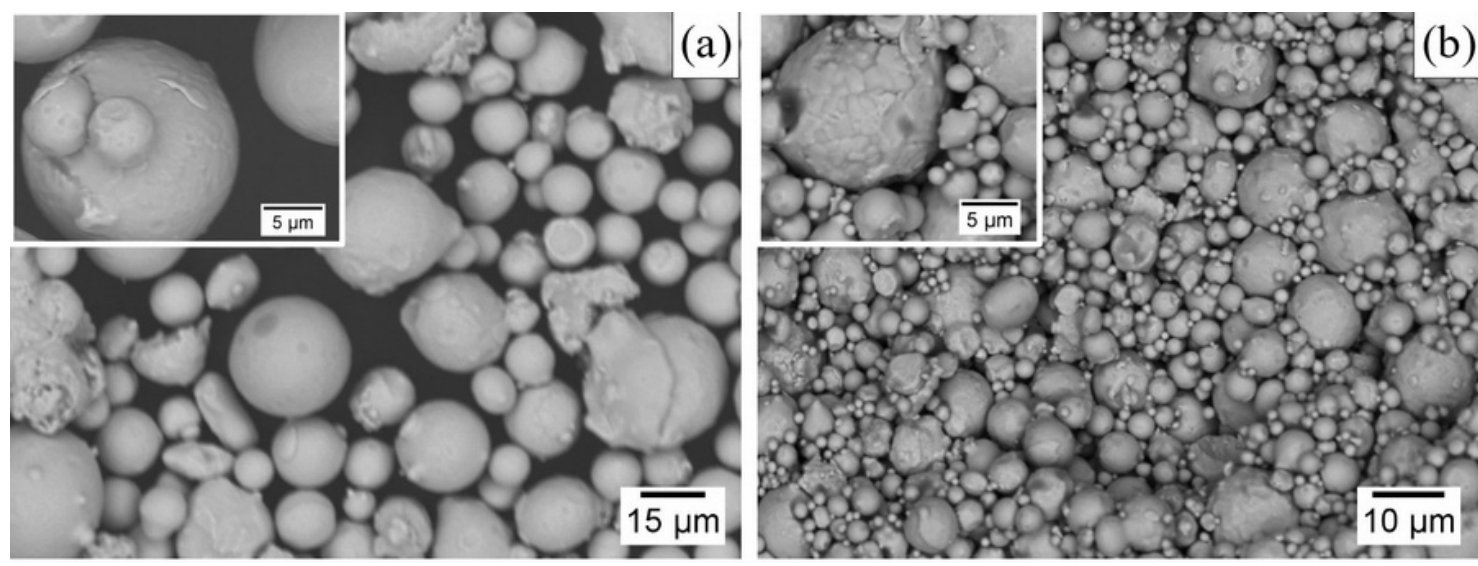

Figure 2. SEM/BSE micrographs of (a) CoCrMoW powder and (b) CoCrMo block.

etched electrolytically with a solution consisting of $100 \mathrm{~mL}$ distilled water and $4 \mathrm{~mL}$ of $\mathrm{HCl}$ under an applied voltage of $5 \mathrm{~V}$ for 3 seconds. The grain size of processed materials were estimated using optical microscopy micrographs and ImageJ software ${ }^{20}$, according to ASTM E112-1421.

SLM and conventionally sintered specimens (CS) from Ceramill Sintron block had their relative density determined using Archimedes principle from $3 \times 3 \times 6 \mathrm{~mm}$ and $5 \times 5 \times 10 \mathrm{~mm}$ specimens, respectively, according to ASTM B962-14. The theoretical density used for SLM and CS materials were 8.5 and $7.9 \mathrm{~g} / \mathrm{cm}^{3}$ respectively.

The coefficient of thermal expansion (CTE) of SLM specimens were determined from $\varnothing 8 \times 4 \mathrm{~mm}$ specimens using a Netzsch DML $402 \mathrm{C}$ dilatometer, adopting $20^{\circ} \mathrm{C} / \mathrm{min}$ heating rate under argon.

Microhardness measurements $(\mathrm{n}=20)$ were performed from SLM and CS specimens using a TIME-Group-China equipment, load of $300 \mathrm{gf}$ for $15 \mathrm{~s}$, from randomly measurements on the surface of each material. Average Vickers hardness values for each material and their respective standard deviations were determined. Tensile tests were performed at room temperature from three specimens for each material (SLM; CS) using an EMIC DL-10000 machine, displacement speed of $0.05 \mathrm{~mm} / \mathrm{min}$ to determine the ultimate tensile strength of both SLM and CS materials.

\section{Results and Discussion}

Figure 2 shows micrographs of the $\mathrm{CoCrMoW}$ powder (Figure 2a) and CoCrMo Ceramill Sintron block (Figure 2b) obtained by SEM/BSE. It can be observed the presence of near spherical particles of different diameters in both materials, which is a characteristic of atomized powder from the liquid. Qualitatively, the average diameter size of the CoCrMoW powder is larger than that used to produce the CoCrMo CAD/CAM block.

Figure 3 shows $\mathrm{XRD}$ results $(\mathrm{Cu}-\mathrm{K} \alpha$ radiation) from CoCrMoW powder, CoCrMo Ceramill Sintron block, SLM and CS specimens. All specimens are single phase materials composed of $\gamma \mathrm{Co}$ (FCC). This $\gamma \mathrm{Co}(\mathrm{FCC})$ is stable at high temperatures based on phase diagram data ${ }^{22}$ and is retained at low temperature due to rapid cooling associated to all processing conditions which produced the materials reported

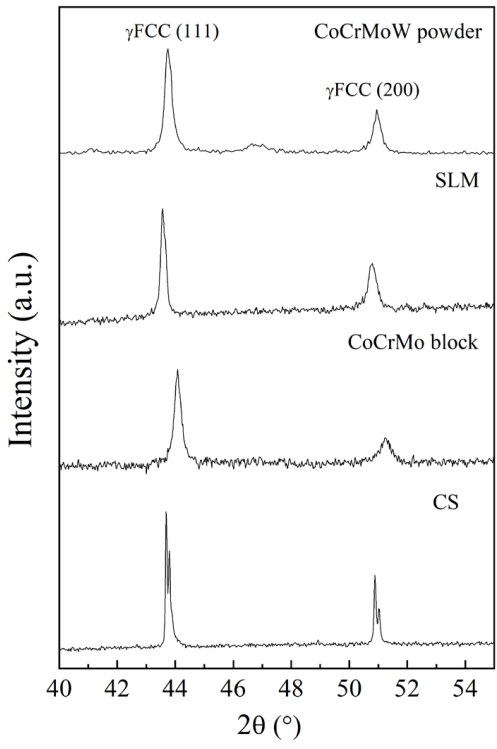

Figure 3. XRD patterns of (a) CoCrMoW powder, (b) SLM specimen, (c) CoCrMo Ceramill Sintron block and (d) CS specimen.

in Figure 3. It should be mentioned that under equilibrium cooling conditions at least some $\varepsilon \mathrm{Co}(\mathrm{HCP})$ should be present at low temperatures.

The SLM specimens reached $95 \%$ of the theoretical density against $85.6 \%$ for the $\mathrm{CS}$ specimens, indicating that the sintering parameters used in the solid-state sintering of compacted CoCrMo block were not suitable for complete elimination of the pores presents in the block.

Metal-ceramic bond is based on a combination of mechanical, chemical and van der Waals forces, and a small CTE mismatch is needed to well attach the veneering ceramic to the CoCrMo alloy surface ${ }^{23}$. The SLM specimens exhibited a CTE of $14.0 \times 10^{-6}{ }^{\circ} \mathrm{C}^{-1}$ which is close to results reported for similar alloys ${ }^{23}$ and suggests good conditions for the application of veneering ceramics.

Figure 4 shows optical micrographs (OM) of a SLM specimen. Figure $4 a$, b shows the top view of the specimen where columnar grains morphology is observed, similar to that from Hedberg et al. ${ }^{24}$ Figure $4 \mathrm{c}, \mathrm{d}$ depicts cross section layered 

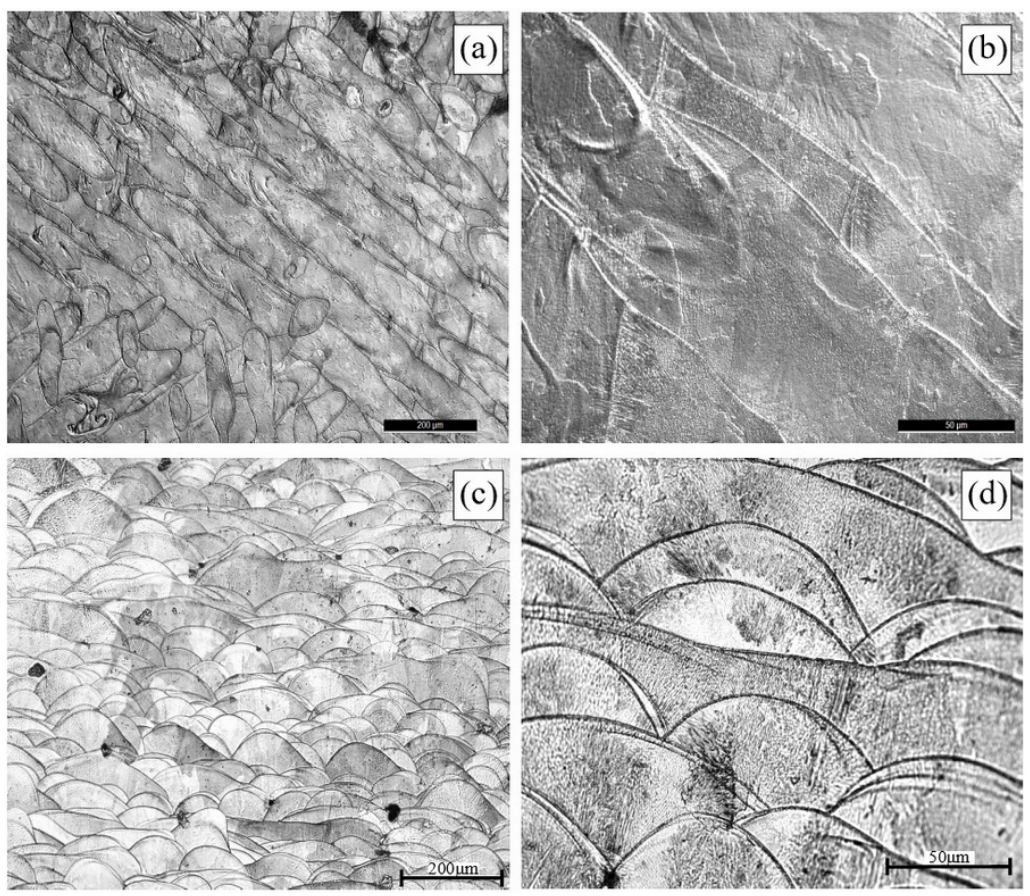

Figure 4. Optical micrographs of a SLM specimen under different magnifications: (a,b) top view; (c,d) cross section view.
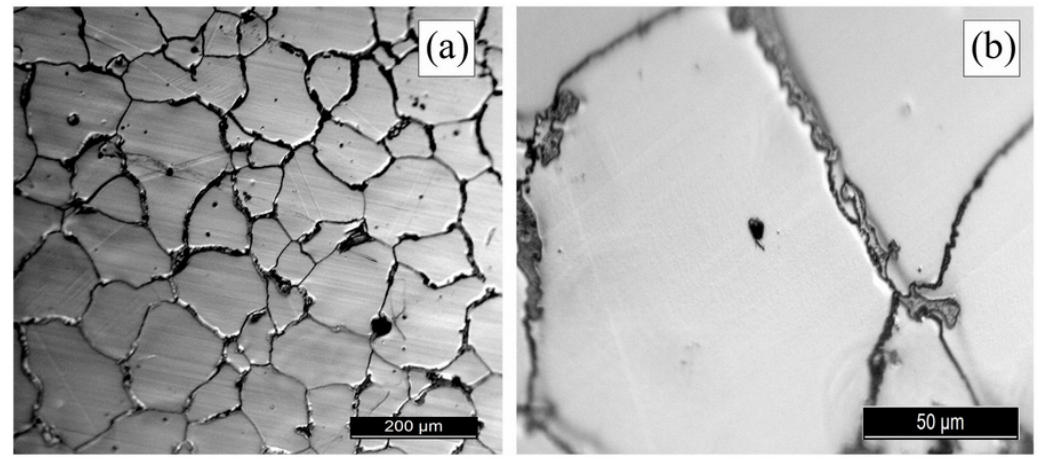

Figure 5. Optical micrographs of a CS specimen $\left(1300^{\circ} \mathrm{C}-1 \mathrm{~h}\right)$ under different magnifications.

structure of the SLM specimen with average grain size of $55 \mu \mathrm{m}$ (length) by $22 \mu \mathrm{m}$ (height), formed by melting/solidification of the powder during the passage of the laser beam. Similar morphology was found for SLM specimens of CoCrMoW alloys from Girardin et al..$^{25}$. Based on these results, some anisotropy in terms of mechanical properties should be expected for the SLM material. As expected, CS specimens presented equiaxial grains with an average grain size of $150 \mu \mathrm{m}$, in addition to some porosity, as shown in Figure 5.

Figure 6 shows hardness values of approximately $400 \mathrm{HV}$ for the SLM specimen, the CS specimen presenting lower values, near $375 \mathrm{HV}$. The difference in hardness values between SLM and CS is associated to differences in chemical composition; morphology; grain size as well as porosity between the two materials. Data from the literature is also included in Figure 6 for comparisons purposes. The hardness values of the SLM specimen are higher than those reported for the ASTM F1537 material as well as the material from

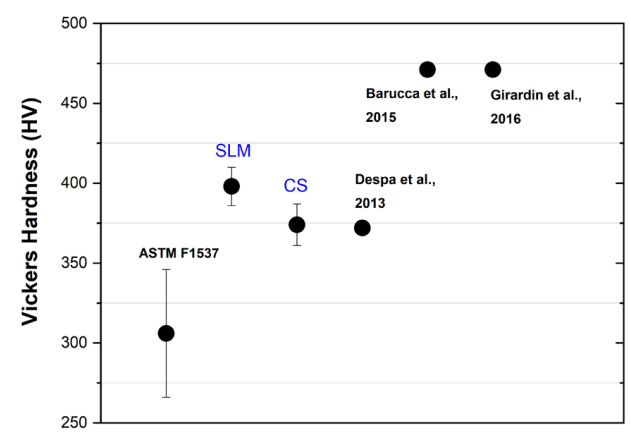

Figure 6. Vickers hardness values of the SLM and CS specimens as well as data from the literature.

Despa et al. work ${ }^{26}$. However, they are lower than those from the investigations of Barucca et al. ${ }^{16}$ and Girardin et al..$^{25}$.

The average UTS values for the SLM and CS specimens were $905 \mathrm{MPa}$ and $780 \mathrm{MPa}$, respectively, 
the lower values from the CS specimens being likely associated to the important porosity level found in this material. Data from SLM specimens in this work are lower than those reported by Despa et al. ${ }^{26}(\sim 1000 \mathrm{MPa})$, Girardin et al. ${ }^{25}(\sim 1290 \mathrm{MPa})$, and Qian et al..$^{18}(\sim 1160 \mathrm{MPa})$, and close to that of Takaichi et al. ${ }^{27}(\sim 950 \mathrm{MPa})$. However, the SLM specimens exhibited average values compatible with the requirements of ISO $22674^{28}$, which determines a minimum value of $500 \mathrm{MPa}$ for applications such as fixed and removable restorations.

\section{Conclusions}

In both investigated manufacturing techniques (CAD/ CAM milling or SLM), the major crystalline phase observed is a $\gamma \mathrm{Co}$ solid solution. $\mathrm{CAD} / \mathrm{CAM}$ samples present relative density close to $86 \%$, with homogeneous equiaxial grains, in addition to some porosity $(>14 \%)$. As a result of this porosity, the values of hardness and tensile strength (UTS) obtained are of the order of $350 \mathrm{HV}$ and $780 \mathrm{MPa}$, respectively. Comparatively, the samples obtained by SLM show higher densification (95.4\%) and better mechanical properties, with hardness and UTS values of $400 \mathrm{HV}$ and $905 \mathrm{MPa}$, respectively. The properties of the developed CoCrMo alloys enable the materials to have properties in agreement with the requirements of ISO 22674 standard ("dentistry metallic restorations"). On the other hand, the microstructural characteristics (anisotropy) of SLM samples and the residual porosity of the CAD/CAM samples are important parameters that can be limiting for new applications, depending on the final requirements for the use of these materials, and might be improved.

\section{Acknowledgements}

The authors thank the mechanical testing laboratory of IME - Military Institute of Engineering, for conducting tensile tests. C. Santos acknowledges Fundação Carlos Chagas Filho de Amparo à Pesquisa do Estado do Rio de Janeiro - FAPERJ for the financial support (E-26/103.216/2011 and E26-202.997/2017) and Financiadora de Estudos e Projetos - FINEP (01.10.0805.00). This study was financed in part by the Coordenacão de Aperfeicoamento de Pessoal de Nível Superior - Brasil (CAPES)- Finance Code 001.

\section{References}

1. Henriques B, Bagheri A, Gasik M, Souza JCMM, Carvalho O, Silva FS, et al. Mechanical properties of hot pressed CoCrMo alloy compacts for biomedical applications. Mater Des. 2015;83:829-34. http://dx.doi.org/10.1016/j.matdes.2015.06.069.

2. Bilgin MS, Erdem A, Dilber E, Ersoy I. Comparison of fracture resistance between cast, $\mathrm{CAD} / \mathrm{CAM}$ milling, and direct metal laser sintering metal post systems. J Prosthodont Res. 2016;60(1):23-8.

3. Chun K, Prior DJ, Waddell JN, Swain MV, Cam CAD. Comparison of the microstructure and phase stability of ascast, $\mathrm{CAD} / \mathrm{CAM}$ and powder metallurgy manufactured $\mathrm{Co}-\mathrm{Cr}$ dental alloys. Dent Mater. 2015;31(12):306-15.

4. Al Jabbari YS, Koutsoukis T, Barmpagadaki X, Zinelis S. Metallurgical and interfacial characterization of PFM Co-Cr dental alloys fabricated via casting, milling or selective laser melting. Dent Mater. 2014;30(4):79-88.
5. Monroy K, Delgado J, Ciurana J. Study of the pore formation on CoCrMo alloys by selective laser melting manufacturing process. Procedia Eng. 2013;63:361-9.

6. Kajima Y, TakaichiA, Nakamoto T, Kimura T, Yogo Y,Ashida M, etal Fatigue strength of Co-Cr-Mo alloy clasps prepared by selective laser melting. J Mech Behav Biomed Mater. 2016;59:446-58.

7. Van Noort R. The future of dental devices is digital. Dent Mater. 2012;28(1):3-12

8. Chen J, Zhang Z, Chen X, Zhang C, Zhang G, Xu Z. Design and manufacture of customized dental implants by using reverse engineering and selective laser melting technology. J Prosthet Dent. 2014;112(5):1088-95.

9. Koutsoukis T, Zinelis S, Eliades G, Al-Wazzan K, Al Rifaiy M, Al Jabbari YS. Selective laser melting technique of Co-Cr dental alloys: a review of structure and properties and comparative analysis with other available techniques. J Prosthodont. 2015;24(4):303-12.

10. Vandenbroucke B, Kruth J. Selective laser melting of biocompatible metals for rapid manufacturing of medical parts. Rapid Prototyping J. 2007;13(4):196-203.

11. Mazzoli A. Selective laser sintering in biomedical engineering. Med Biol Eng Comput. 2013;51(3):245-56.

12. Williams JM, Adewunmi A, Schek RM, Flanagan CL, Krebsbach PH, Feinberg SE, et al. Bone tissue engineering using polycaprolactone scaffolds fabricated via selective laser sintering. Biomaterials. 2005;26(23):4817-27.

13. Simchi A. Direct laser sintering of metal powders: Mechanism, kinetics and microstructural features. Mater Sci Eng A. 2006;428(1-2):148-58.

14. Van Hooreweder B, Lietaert K, Neirinck B, Lippiatt N, Wevers M. CoCr F75 scaffolds produced by additive manufacturing: influence of chemical etching on powder removal and mechanical performance. J Mech Behav Biomed Mater. 2017;70:60-7. http://dx.doi.org/10.1016/j.jmbbm.2017.03.017.

15. Liverani E, Fortunato A, Leardini A, Belvedere C, Siegler S, Ceschini L, et al. Fabrication of Co-Cr-Mo endoprosthetic ankle devices by means of Selective Laser Melting (SLM). Mater Des. 2016;106:60-8. http://dx.doi.org/10.1016/j. matdes.2016.05.083.

16. Barucca G, Santecchia E, Majni G, Girardin E, Bassoli E, Denti $\mathrm{L}$, et al. Structural characterization of biomedical $\mathrm{Co}-\mathrm{Cr}-\mathrm{Mo}$ components produced by directmetal laser sintering. Mater Sci Eng C. 2015;48:263-9.

17. Zhou Y, Wei W, Yan J, Liu W, Li N, Li H, et al. Microstructures and metal-ceramic bond properties of $\mathrm{Co}-\mathrm{Cr}$ biomedical alloys fabricated by selective laser melting and casting. Mater Sci Eng A. 2019;759(May):594-602. http://dx.doi.org/10.1016/j. msea.2019.05.085.

18. Qian B, Saeidi K, Kvetková L, Lofaj F, Xiao C, Shen Z. Defects-tolerant Co-Cr-Mo dental alloys prepared by selective laser melting. Dent Mater. 2015;31(12):1435-44. http://dx.doi. org/10.1016/j.dental.2015.09.003.

19. Siegrist T. Crystallographica - a software toolkit for crystallography. J Appl Cryst. 1997;30(3):418-9.

20. Abràmoff MD, Magalhães PJ, Ram SJ. Image processing with imageJ. Biophoton Int. 2004;11(7):36-41.

21. ASTM: American Society for Testing and Materials. ASTM E112 - Standard Test Methods for Determining Average Grain Size. West Conshohocken: ASTM International; 2014. p. 1-28.

22. Gupta KP. The Co-Cr-Mo (Cobalt-Chromium-Molybdenum) system. J Phase Equilibria Diffus. 2005;26(1):87-92.

23. Stawarczyk B, Eichberger M, Hoffmann R, Noack F, Schweiger J, Beuer F. A Novel CAD/CAM base metal compared to conventional CoCrMo alloys: an in-vitro study of the longterm metal-ceramic bond strength. Oral Health Dent Manag. 2014;23(2):446-52.

24. Hedberg YS, Qian B, Shen Z, Virtanen S, Odnevall Wallinder I. In vitro biocompatibility of $\mathrm{CoCrMo}$ dental alloys fabricated 
by selective laser melting. Dent Mater. 2014;30(5):525-34. http://dx.doi.org/10.1016/j.dental.2014.02.008.

25. Girardin E, Barucca G, Mengucci P, Fiori F, Bassoli E, Gatto A, et al. Biomedical Co-Cr-Mo components produced by direct metal laser sintering. Mater Today Proc. 2016;3(3):889-97.

26. Despa V, Catangiu A, Ivan IA. Mechanical characteristics of CoCrMo alloys manufactured by selective laser sintering technology. Sci Bull VALAHIA Univ - Mater Mech. 2013;8(8):29-32.
27. Takaichi A, Suyalatu, Nakamoto T, Joko N, Nomura N, Tsutsumi $\mathrm{Y}$, et al. Microstructures and mechanical properties of Co-29Cr$6 \mathrm{Mo}$ alloy fabricated by selective laser melting process for dental applications. J Mech Behav Biomed Mater. 2013;21:67-76.

28. ISO: International Organization for Standardization. ISO 22674:2016 - Dentistry -Metallic materials for fixed and removable restorations and appliances. 2 nd ed. Genebra: ISO; 2016. $36 \mathrm{p}$. 